\title{
Efficacy and safety of ramosetron versus ondansetron for postoperative nausea and vomiting after general anesthesia: a meta-analysis of randomized clinical trials
}

\author{
This article was published in the following Dove Press journal: \\ Drug Design, Development and Therapy \\ 23 April 2015 \\ Number of times this article has been viewed
}

\author{
Chengjie Gao \\ Bo Li \\ Lufeng Xu \\ Fubin Lv \\ Guimao Cao \\ Huixia Wang \\ Fei Wang \\ Guanghan Wu \\ Department of Anesthesiology, \\ General Hospital of Jinan Military \\ Command, Jinan, People's Republic \\ of China
}

\begin{abstract}
Background: Postoperative nausea and vomiting is a common side effect of general anesthesia. In this study, we performed a meta-analysis on the efficacy and safety of ramosetron versus ondansetron in the prevention of postoperative nausea and vomiting using the most recently published randomized controlled clinical studies.

Methods: PubMed and EMBASE were searched for randomized controlled clinical trials comparing the efficacy and safety of ramosetron and ondansetron. The meta-analysis was performed using Review Manager version 5.3 (Cochrane Collaboration, Oxford, UK). Dichotomous outcomes are presented as the relative risk (RR) with a 95\% confidence interval (CI).

Results: A total of 898 patients from nine selected studies were treated with antiemetics after surgery, including 450 patients who received ondansetron $4 \mathrm{mg}$ and 448 patients who received ramosetron $0.3 \mathrm{mg}$. The meta-analysis showed no statistically significant difference between the two groups with regard to prevention of postoperative nausea (PON) during different time periods in the 48 hours after surgery. When comparing the efficacy of ramosetron and ondansetron in the prevention of postoperative vomiting (POV), at various time intervals in the 24 hours after surgery, ramosetron was significantly more efficient than ondansetron: $0-6$ hours (RR $0.46,95 \%$ CI 0.24-0.92; $P=0.03$ ), 0-24 hours (RR 0.72, 95\% CI 0.52-1.00; $P=0.05$ ), and 6-24 hours (RR $0.51,95 \%$ CI $0.31-0.84 ; P=0.008)$. At other time periods between 24 and 48 hours after surgery, ramosetron did not show better efficacy than ondansetron. When comparing the safety profiles of ramosetron and ondansetron, fewer side effects were recorded in the ramosetron group (RR $0.65,95 \%$ CI $0.47-0.91 ; P=0.01)$.
\end{abstract}

Conclusion: Our meta-analysis demonstrates that ramosetron was more effective than ondansetron in the prevention of early POV (0-24 hours) with fewer recorded side effects. However, our study did not reveal any statistically significant differences in efficacy between ramosetron and ondansetron in the prevention of PON or late POV (at 24-48 hours).

Keywords: ramosetron, ondansetron, postoperative nausea and vomiting, general anesthesia, meta-analysis

\section{Introduction}

Postoperative nausea and vomiting (PONV) is a common side effect after general anesthesia, with an incidence of around $30 \% .{ }^{1}$ Risk factors for PONV are both anesthesiarelated and non-anesthesia-related. Clinical studies show that the anesthesia-related risk factors for PONV are use of volatile anesthetics and postoperative opioid analgesics. ${ }^{2}$ However, the mechanism underlying these two primary risk factors is currently not well understood. ${ }^{3}$ Non-anesthesia-related risk factors for PONV include female sex,
Correspondence: Chengjie Gao Department of Anesthesiology, General Hospital of Jinan Military Command, 25 Shifan Road, Jinan, Shandong 25003I, People's Republic of China Email gaochjmd@yeah.net 
history of PONV or motion sickness, being a non-smoker, and younger age. ${ }^{2}$

Although PONV is not a life-threatening medical complication, failure to control PONV substantially increases the time to discharge, resource utilization of the post-anesthesia care unit, and cost of medical care. ${ }^{4}$ Antiemetic drugs used to control PONV include cholinergic receptor antagonists, histamine receptor antagonists, serotonin antagonists, dopamine antagonists, and NK1 antagonists. ${ }^{3,5}$ Serotonin type 3 (5-HT3) receptor antagonists are the antiemetic drugs most commonly used in post-anesthesia care. The first line of choice among the 5-HT3 receptor antagonists is ondansetron. ${ }^{6}$ However, recent cardiac safety concerns regarding ondansetron limit its use in certain anesthesia settings if a high dose is required. ${ }^{7}$ Ramosetron is a newly developed 5-HT3 receptor antagonist which shows more prolonged activity than ondansetron and is very effective in preventing PONV.$^{8-11}$ To provide an updated evaluation of the effectiveness of ramosetron, we performed a meta-analysis on the efficacy and safety of ramosetron versus ondansetron using the most recently published randomized controlled clinical studies.

\section{Materials and methods}

\section{Search strategy, selection criteria, and study quality assessment}

We searched the PubMed and EMBASE databases up to November 2014 for relevant clinical studies. Search terms used for PubMed were: ("ramosetron" [Supplementary Concept] OR "ramosetron" [All Fields]) AND ("ondansetron" [MeSH Terms] OR “ondansetron" [All Fields]) AND ("postoperative nausea and vomiting" [MeSH Terms] OR ("postoperative" [All Fields] AND "nausea" [All Fields] AND "vomiting" [All Fields]) OR "postoperative nausea and vomiting" [All Fields] OR "ponv" [All Fields]). Search terms used for EMBASE were: postoperative vomiting/or postoperative complication/or ondansetron/or ramosetron/ or nausea/or vomiting/AND randomized clinical trial ramosetron.ti,ab./AND *ondansetron/and *ramosetron/. Clinical studies in the reference lists of recent published trials with retrievable full text were also searched. Randomized controlled clinical trials comparing the efficacy and safety profiles of ramosetron and ondansetron were selected by title and abstract screening followed by full text retrieval. Reviews, conference abstracts, and non-English language articles were excluded. Only studies using standard doses of ramosetron ( $4 \mathrm{mg}$ ) and ondansetron $(0.3 \mathrm{mg})$ without dexamethasone as an adjunct were selected for meta-analysis. Two authors $(\mathrm{CG}, \mathrm{BL})$ independently performed the search and selected the relevant studies. Any discrepancy in the final selection was resolved by group discussion between all authors. The quality of the selected studies was assessed using the Jadad scoring system, which evaluates the randomization strategy, controls included, and description of withdrawal and dropouts in the study period. A study with a Jadad score $\geq 3$ is regarded as being of high quality. ${ }^{12}$

\section{Data extraction, outcomes, and statistical analysis}

Data extracted from each selected study were: author, year of publication, study design, number of patients analyzed, type of anesthesia, type of surgery, treatment regimen for ramosetron and ondansetron, and primary and secondary outcomes. The primary outcome was the incidence of postoperative nausea (PON) and postoperative vomiting (POV). The secondary outcome was side effects following administration of ramosetron or ondansetron, including headache, dizziness, and drowsiness. The meta-analysis was performed using Review Manager version 5.3 (Cochrane Collaboration, Oxford, UK). Dichotomous outcomes are presented as the relative risk (RR) with a $95 \%$ confidence interval $(\mathrm{CI})$. The presence of heterogeneity was evaluated with the $I^{2}$ statistic. $P<0.05$ was considered to be statistically significant and a random-effects model was used for the meta-analysis. Fixedeffects model was used if heterogeneity was not significant across selected studies.

\section{Results}

\section{Study identification and characteristics}

We identified a total of 68 records using our search strategy. Studies published by Yoshitaka Fujii were excluded due to concerns raised by other investigators. ${ }^{10,11}$ After initial title and abstract screening and full text retrieval, only nine studies met our selection criteria and were eligible for meta-analysis ${ }^{13-21}$ (Figure 1). The characteristics of the selected studies are summarized in Table 1. Most of these studies were very well designed randomized controlled clinical trials, with a Jadad score of 4 or 5 .

\section{Outcomes}

\section{Primary outcomes: PON and POV}

A total of 898 patients from nine selected studies were treated with antiemetics after surgery, including 450 patients who received ondansetron $4 \mathrm{mg}$ and 448 patients who received ramosetron $0.3 \mathrm{mg}$. PON and POV events were recorded at different time intervals in the nine studies. Meta-analysis of 


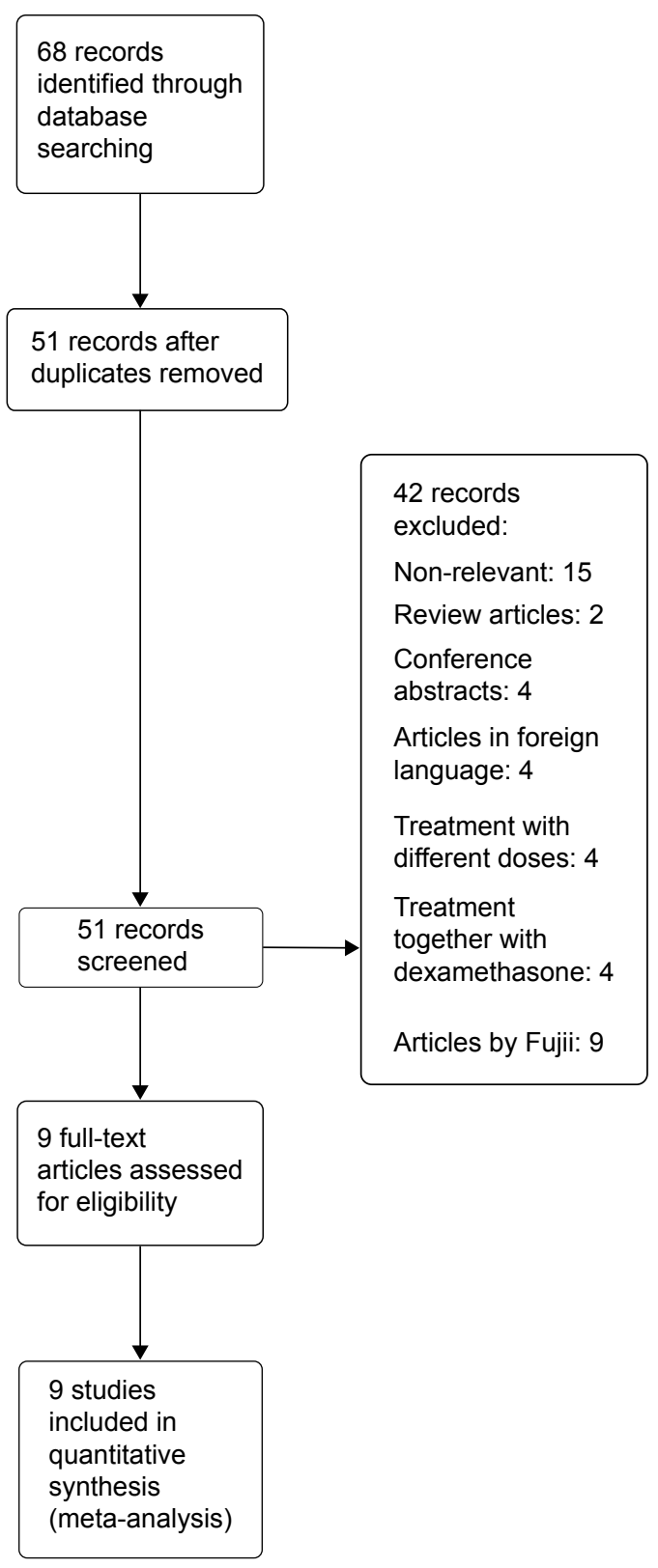

Figure I Flow diagram of study selection.

results showed no statistically significant difference in PON between patients receiving ramosetron and those receiving ondansetron in the different time periods in the 24 hours after surgery: $0-2$ hours (RR $0.54,95 \%$ CI $0.23-1.25 ; P=0.15$ ), 0-6 hours (RR 0.84, 95\% CI 0.44-1.63; $P=0.61$ ), 0-24 hours (RR 0.89, 95\% CI 0.63-1.27; $P=0.53$ ), 2-24 hours (RR 0.47, 95\% CI $0.15-1.49 ; P=0.2$ ), or 6-24 hours (RR $0.88,95 \%$ CI $0.58-1.35 ; P=0.56)$. However, ramosetron had a tendency to be more effective than ondansetron during the 24-48-hour time period after surgery, but this effect did not reach statistical significance (RR 0.60, 95\% CI 0.36-1.01; $P=0.06$ ), (Figure 2). Ramosetron had different effects versus ondansetron on POV as compared with PON. During some of the time periods in the 24 hours after surgery, ramosetron showed higher efficacy than ondansetron for POV: $0-6$ hours (RR 0.46, 95\% CI 0.24-0.92; $P=0.03$ ), $0-24$ hours (RR $0.72,95 \%$ CI $0.52-1.00 ; P=0.05$ ) and 6-24 hours (RR $0.51,95 \%$ CI $0.31-0.84 ; P=0.008$ ). At other time periods, including the $24-48$ hours after surgery, ramosetron was no more effective than ondansetron in prevention of POV: $0-2$ hours (RR 0.67, 95\% CI 0.11-4.00; $P=0.66$ ), 2-6 hours (RR 0.55, 95\% CI 0.21-1.47; $P=0.24$ ), 2-24 hours (RR 0.37, 95\% CI 0.10-1.35; $P=0.13$ ), and 24-48 hours (RR $0.51,95 \%$ CI $0.17-1.51 ; P=0.22$, Figure 3$)$. We did not include the study by Banerjee et al ${ }^{22}$ in our meta-analysis because these authors did not provide detailed PON and POV outcomes. However, their results showed that preoperative administration of a single intravenous dose of ramosetron $0.3 \mathrm{mg}$ was more effective than a single intravenous dose of ondansetron $4 \mathrm{mg}$ in reducing the incidence of PONV in general in the 18 hours after surgery.

\section{Secondary outcome: side effects of ramosetron and ondansetron}

Four studies presented full data on side effects (headache, dizziness, drowsiness) after treatment with ramosetron or ondansetron in the 48 hours after surgery. ${ }^{13,15,17,21}$ Ramosetron had fewer recorded side effects than ondansetron (RR 0.65, 95\% CI 0.47-0.91; $P=0.01$, Figure 4). Other studies did not present detailed data on side effects, but mentioned in their results that there was no statistically significant difference between ramosetron and ondansetron.

\section{Publication bias}

The potential publication bias of the selected studies was assessed using a Begg's funnel plot. No publication bias was detected for the time periods of 0-24 hours, 6-24 hours, and 24-48 hours. There was some publication bias concerning data for other time periods after surgery (Figure 5).

\section{Discussion}

The previous positive clinical results published by Fujii et al on the efficacy of ramosetron have been criticized and reevaluated. ${ }^{10,11}$ The most recent meta-analysis by Mihara et al showed no significant difference between ramosetron and ondansetron in the prevention of PON. ${ }^{10}$ They found ramosetron was much more effective in the prevention of POV than ondansetron. Consistent with their results for PON, our meta-analysis showed no statistically significant difference between ramosetron and ondansetron in the prevention of PON during any of the time periods in the 


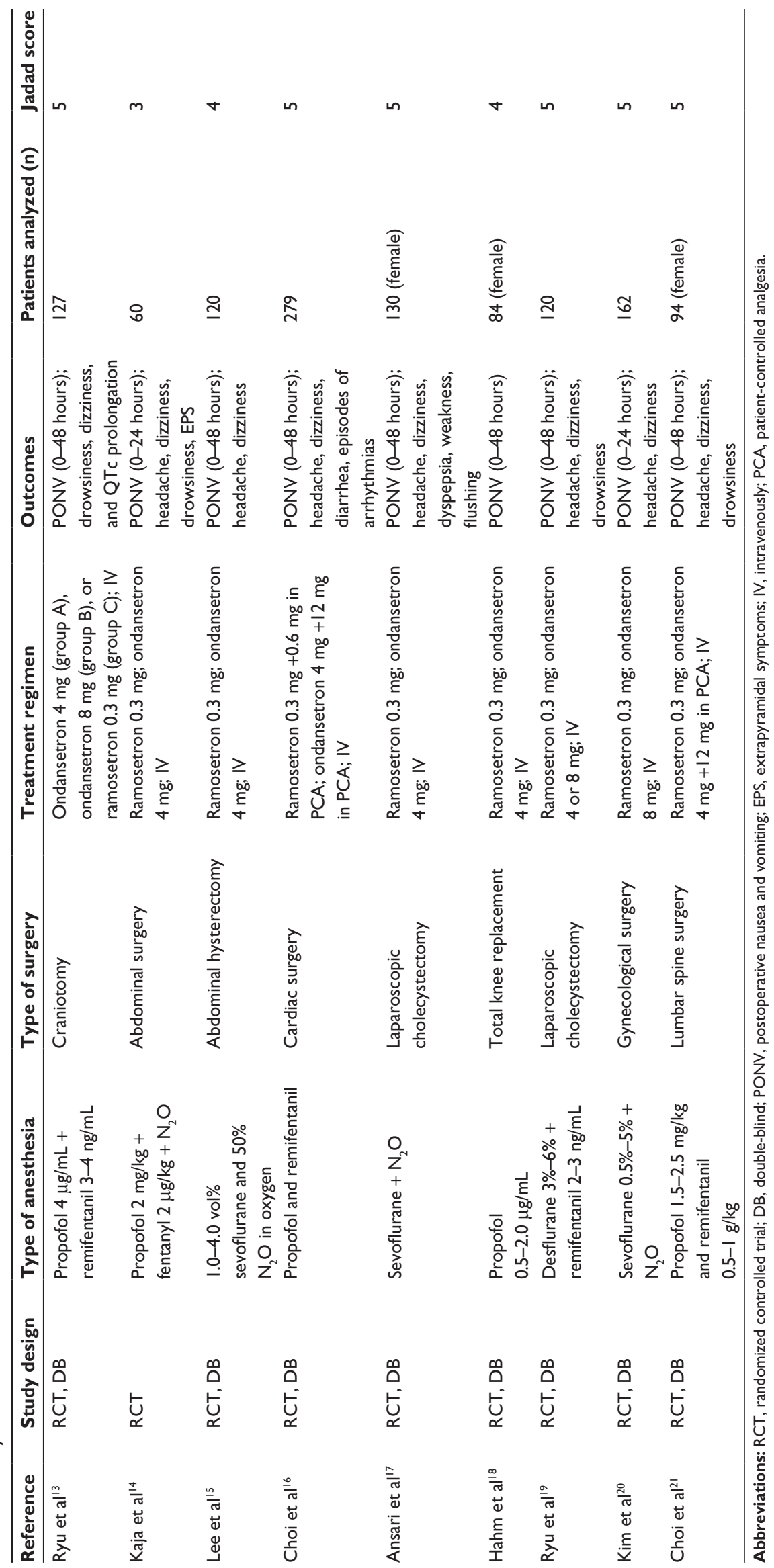




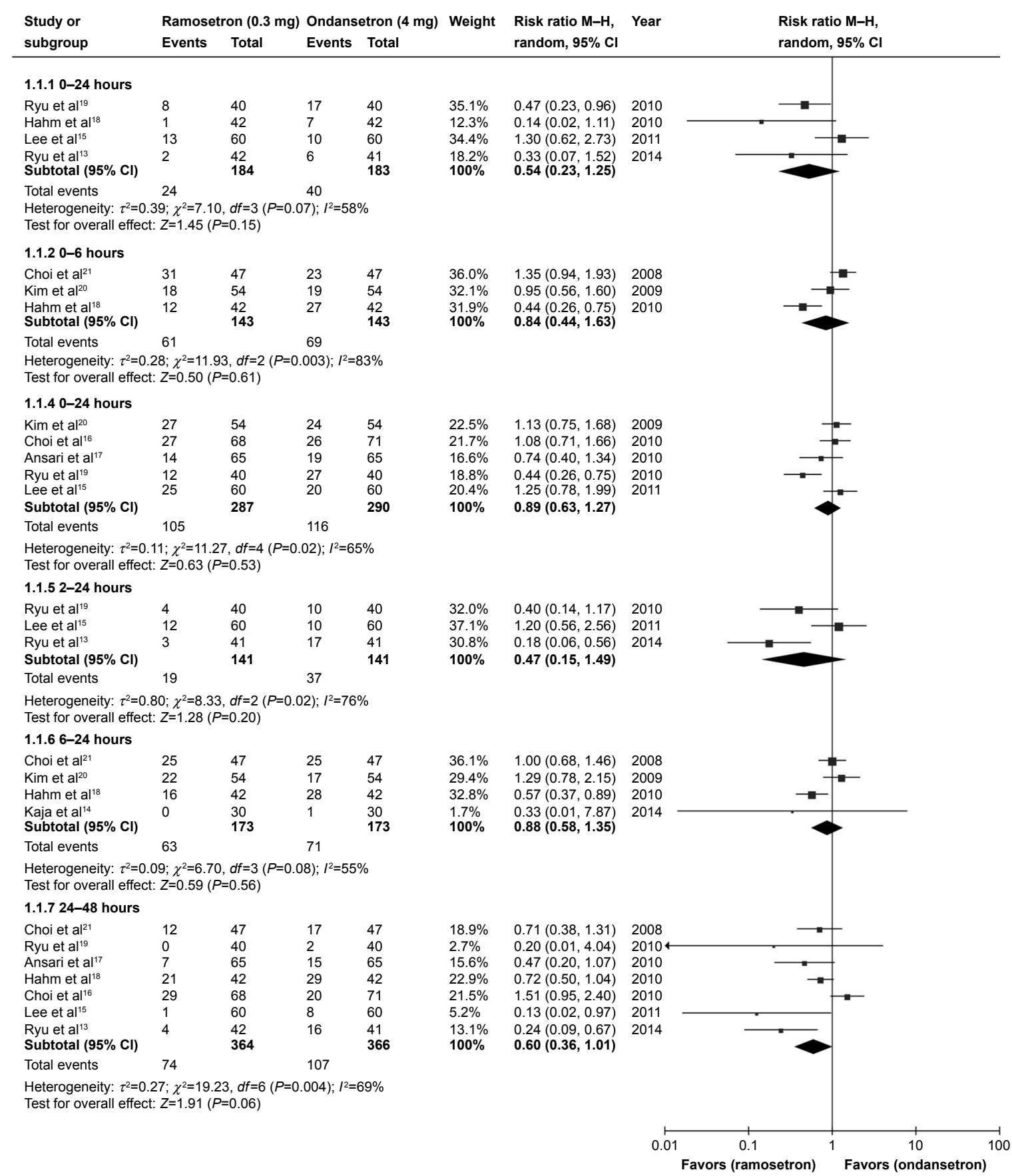

Figure 2 Forest plot of relative risk comparing postoperative nausea between ramosetron and ondansetron treatment.

Abbreviations: $\mathrm{Cl}$, confidence interval; $\mathrm{M}-\mathrm{H}$, Mantel-Haenszel test.

48 hours after surgery, although ramosetron had a tendency to be more effective than ondansetron in the $24-48$ hours after treatment. During some of the time periods in the 24 hours after surgery, we found a statistically significant difference between ramosetron and ondansetron with regard to prevention of POV (0-6 hours, 0-24 hours, and 6-24 hours). However, we did not find any difference between these two treatments in the 24-48-hour interval after surgery. To explore the cause for the inconsistency between our results and those of Mihara et al with regard to the ability of ramosetron to prevent late POV (24-48 hours), we compared the selected studies and the data extracted for late POV between our meta-analysis and that by Mihara et al. We included two new studies in our analysis ${ }^{13,17}$ and excluded a study by Choi et al ${ }^{23}$ that had been selected by Mihara et al. The study reported by Choi et al used dexamethasone as an adjunct to ramosetron and ondansetron for the treatment of PONV. Given that all other selected studies 


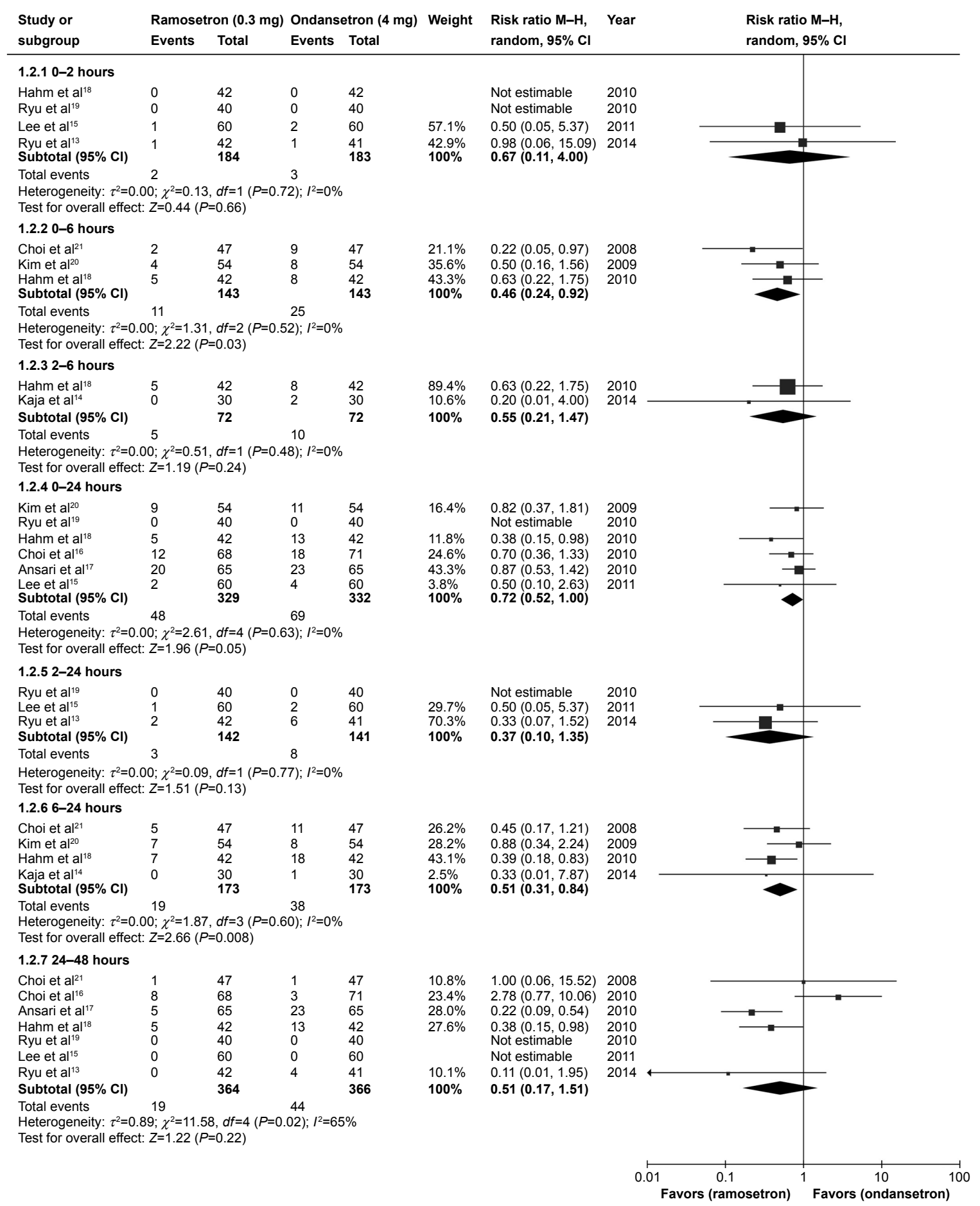

Figure 3 Forest plot of relative risk comparing postoperative vomiting between ramosetron and ondansetron treatment.

Abbreviations: $\mathrm{Cl}$, confidence interval; $\mathrm{M}-\mathrm{H}$, Mantel-Haenszel test.

used only ramosetron or ondansetron, it was inappropriate to include a study with a different regimen. We also found a data extraction error in the meta-analysis by Mihara et al ie, in one selected study, ${ }^{16}$ late POV events in the ondansetron group were actually fewer than in the ramosetron group, according to line graph in the original study; however, in the publication by Mihara et al POV events in the ondansetron group were reported to be more common than in the ramosetron group (17 versus nine, respectively).

When comparing the total number of side effects including headache, dizziness, and drowsiness, ramosetron caused 


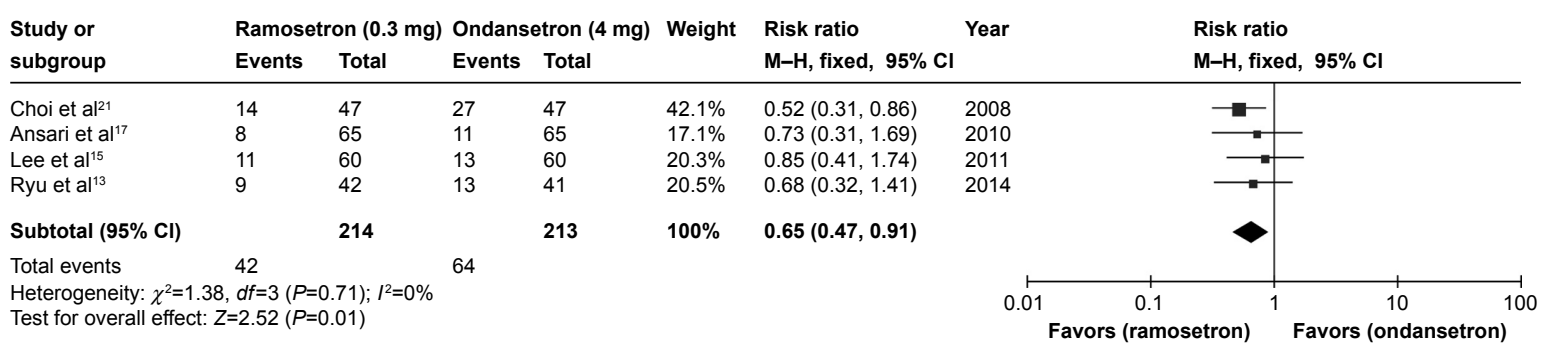

Figure 4 Forest plot of relative risk comparing side effects between ramosetron and ondansetron treatment. Abbreviations: $\mathrm{Cl}$, confidence interval; $\mathrm{M}-\mathrm{H}$, Mantel-Haenszel test.

fewer recorded side effects than ondansetron in the 48 hours after surgery. In view of the US Food and Drug Administration warnings regarding the use of ondansetron in patients with a prolonged QT interval, ${ }^{24}$ improved safety would be a good reason to replace ondansetron with ramosetron, even though there was no significant difference in efficacy between these two treatments.

Our meta-analysis has some limitations. The total number of patients analyzed was only 898 , with PON and POV events recorded at different time periods in the different studies, so the sample size for each time period was very small. Further, ramosetron is only licensed in Asian countries, with the selected studies all being conducted in Asian population, and it is unclear whether our conclusion is applicable to other populations. Finally, we detected some publication bias in the data on PON and POV events during some time periods in the 24 hours following surgery. Therefore, results for those time periods may not be accurate.

In summary, our current meta-analysis demonstrates that ramosetron was much more effective than ondansetron in the prevention of early POV (0-24 hours) and was associated with fewer side effects. However, our study did not identify any statistically significant differences in efficacy between ramosetron and ondansetron in the prevention of PON and late POV (24-48 hours).

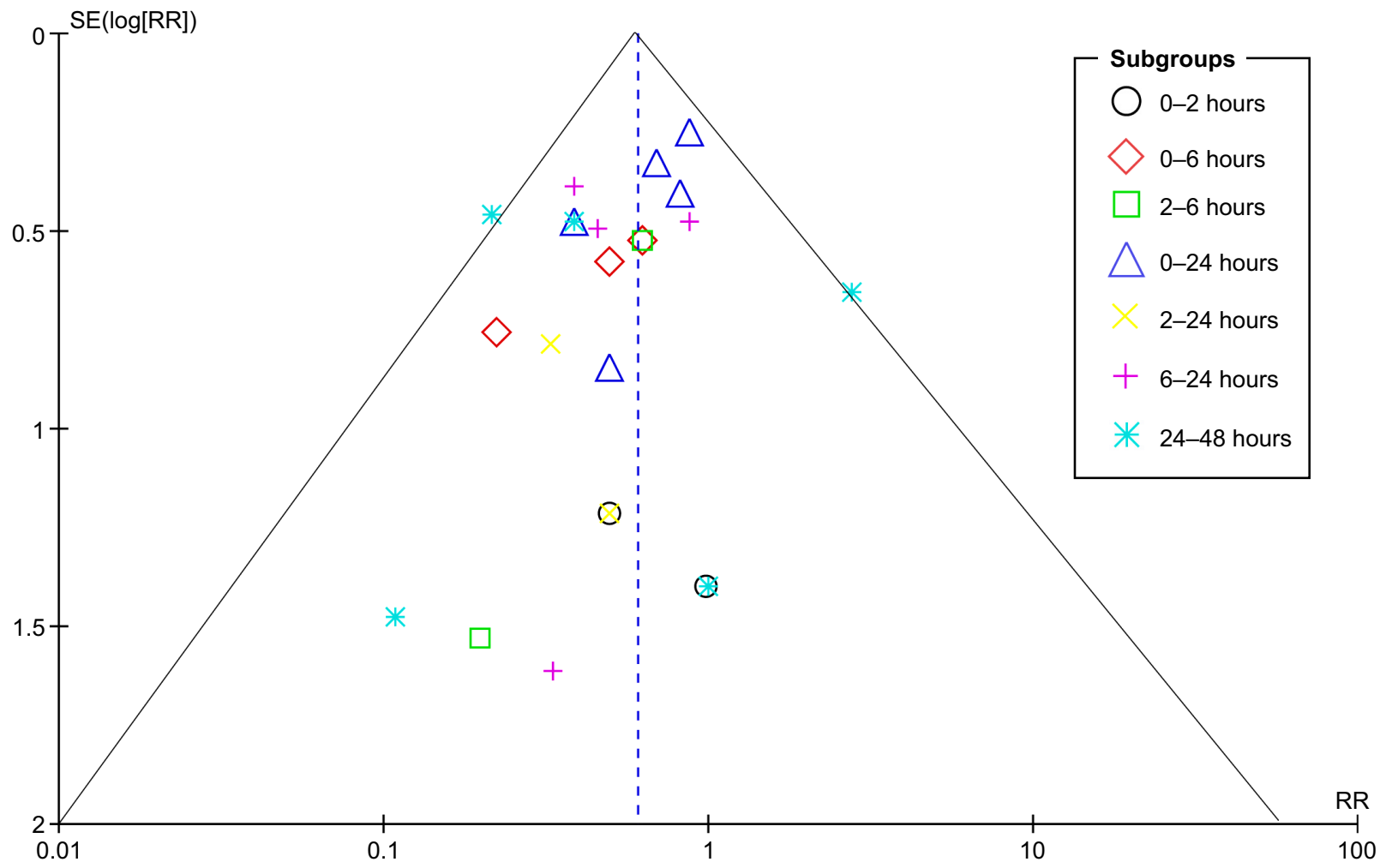

Figure 5 Funnel plot for the assessment of publication bias. Abbreviations: RR, relative risk; SE, standard error. 


\section{Disclosure}

The authors report no conflicts of interest in this work.

\section{References}

1. Franck M, Radtke FM, Apfel CC, et al. Documentation of postoperative nausea and vomiting in routine clinical practice. $J$ Int Med Res. 2010;38:1034-1041.

2. Apfel CC, Heidrich FM, Jukar-Rao S, et al. Evidence-based analysis of risk factors for post-operative nausea and vomiting. Br J Anaesth. 2012;109:742-753.

3. Horn CC, Wallisch WJ, Homanics GE, Williams JP. Pathophysiological and neurochemical mechanisms of postoperative nausea and vomiting. Eur J Pharmacol. 2014;722:55-66.

4. Habib AS, Chen YT, Taguchi A, Hu XH, Gan TJ. Postoperative nausea and vomiting following inpatient surgeries in a teaching hospital: a retrospective database analysis. Curr Med Res Opin. 2006;22:1093-1099.

5. Moon YE. Postoperative nausea and vomiting. Korean J Anesthesiol. 2014;67:164-170

6. Cox F. Systematic review of ondansetron for the prevention and treatment of postoperative nausea and vomiting in adults. BrJ Theatre Nurs. 1999;9:556-563.

7. Doggrell SA, Hancox JC. Cardiac safety concerns for ondansetron, an antiemetic commonly used for nausea linked to cancer treatment and following anaesthesia. Expert Opin Drug Saf. 2013;12:421-431.

8. Rabasseda X. Ramosetron, a 5-HT3 receptor antagonist for the control of nausea and vomiting. Drugs Today (Barc). 2002;38:75-89.

9. Kim WO, Koo BN, Kim YK, Kil HK. Ramosetron for the prevention of postoperative nausea and vomiting (PONV): a meta-analysis. Korean J Anesthesiol. 2011;61:405-412.

10. Mihara T, Tojo K, Uchimoto K, Morita S, Goto T. Reevaluation of the effectiveness of ramosetron for preventing postoperative nausea and vomiting: a systematic review and meta-analysis. Anesth Analg. 2013; 117:329-339.

11. Carlisle JB. A meta-analysis of prevention of postoperative nausea and vomiting: randomised controlled trials by Fujii et al compared with other authors. Anaesthesia. 2012;67:1076-1090.

12. Jadad AR, Moore RA, Carroll D, et al. Assessing the quality of reports of randomized clinical trials: is blinding necessary? Control Clin Trials. 1996;17:1-12.

13. Ryu JH, Lee JE, Lim YJ, et al. A prospective, randomized, double-blind, and multicenter trial of prophylactic effects of ramosetron on postoperative nausea and vomiting (PONV) after craniotomy: comparison with ondansetron. BMC Anesthesiol. 2014;14:63.
14. Kaja S, Giri RS, Tugave DV, Iqbal M. A randomized clinical trial comparing the efficacy and safety of ramosetron versus ondansetron in patients undergoing abdominal surgery under general anesthesia. Saudi J Anaesth. 2014;8:59-63.

15. Lee JW, Park HJ, Choi J, Park SJ, Kang H, Kim EG. Comparison of ramosetron's and ondansetron's preventive anti-emetic effects in highly susceptible patients undergoing abdominal hysterectomy. Korean J Anesthesiol. 2011;61:488-492.

16. Choi DK, Chin JH, Lee EH, et al. Prophylactic control of post-operative nausea and vomiting using ondansetron and ramosetron after cardiac surgery. Acta Anaesthesiol Scand. 2010;54:962-969.

17. Ansari MM, Siddiqui OA, Haleem S, Varshney R, Akhtar S, Khan FA. Comparison of ramosetron and ondansetron for control of post-operative nausea and vomiting following laparoscopic cholecystectomy. Indian J Med Sci. 2010;64:272-280.

18. Hahm TS, Ko JS, Choi SJ, Gwak MS. Comparison of the prophylactic anti-emetic efficacy of ramosetron and ondansetron in patients at highrisk for postoperative nausea and vomiting after total knee replacement. Anaesthesia. 2010;65:500-504.

19. Ryu J, So YM, Hwang J, Do SH. Ramosetron versus ondansetron for the prevention of postoperative nausea and vomiting after laparoscopic cholecystectomy. Surg Endosc. 2010;24:812-817.

20. Kim SI, Kim SC, Baek YH, Ok SY, Kim SH. Comparison of ramosetron with ondansetron for prevention of postoperative nausea and vomiting in patients undergoing gynaecological surgery. Br J Anaesth. 2009;103: 549-553.

21. Choi YS, Shim JK, Yoon DH, Jeon DH, Lee JY, Kwak YL. Effect of ramosetron on patient-controlled analgesia related nausea and vomiting after spine surgery in highly susceptible patients: comparison with ondansetron. Spine (Phila Pa 1976). 2008;33:E602-E606.

22. Banerjee D, Das A, Majumdar S, et al. PONV in ambulatory surgery: a comparison between ramosetron and ondansetron: a prospective, double-blinded, and randomized controlled study. Saudi J Anaesth. 2014;8:25-29.

23. Choi YS, Shim JK, Ahn SH, Kwak YL. Efficacy comparison of ramosetron with ondansetron on preventing nausea and vomiting in high-risk patients following spine surgery with a single bolus of dexamethasone as an adjunct. Korean J Anesthesiol. 2012;62:543-547.

24. Food and Drug Administration. FDA Drug Safety Communication: Abnormal heart rhythms may be associated with use of Zofran (ondansetron), 2011. Available from: http://www.fda.gov/Drugs/DrugSafety/ ucm271913.htm. Accessed March 18, 2015.
Drug Design, Development and Therapy

\section{Publish your work in this journal}

Drug Design, Development and Therapy is an international, peerreviewed open-access journal that spans the spectrum of drug design and development through to clinical applications. Clinical outcomes, patient safety, and programs for the development and effective, safe, and sustained use of medicines are a feature of the journal, which

\section{Dovepress}

has also been accepted for indexing on PubMed Central. The manuscript management system is completely online and includes a very quick and fair peer-review system, which is all easy to use. Visit http://www.dovepress.com/testimonials.php to read real quotes from published authors. 